\title{
Evaluation of Patient Rights Practice among Doctors in Gynaecology and Obstetrics Department in Zagazig General Hospital
}

\author{
${ }^{1}$ Ghada Mahmoud, ${ }^{2}$ Doaa Sabry Shabanaa, ${ }^{3}$ Shereen Mohammed Bahgat, ${ }^{4}$ Mohamed \\ Adel Fouda
}

${ }^{1}$ Public Health Department, Faculty of Medicine, Zagazig University, ${ }^{2}$ Sharkia health directorate, Egypt. ${ }^{3}$ Family Medicine Department, Faculty of Medicine, Zagazig University, Egypt. ${ }^{4}$ Public Health Department, Faculty of Medicine, Zagazig University, Egypt.

\begin{abstract}
Background: The key competency of health professionals is their ability to protect the health of individuals. The recent developments of the healthcare systems lead to increased hazards in medical practice which raise the importance of knowing and practicing the patient rights. Objective: To evaluate the effect of a training program to improve awareness and knowledge of doctors about patient rights in Zagazig general hospital. Method: The current study is an interventional study that was conducted in Zagazig general hospital. A total of 70 physicians were evaluated regarding patient rights then a training program was conducted and evaluated three months later. The collected data were analyzed by SPSS program version 20 considering statistical significance when $P$ value $<0.05$. Results: Only $51.4 \%$ of the studied physicians were aware about patients' rights. There was poor attention to patients' rights' practice as more than half of the study population rarely or never paid attention to patients' rights during practice. About $50 \%$ of participants perceived that patients' rights have influence on medical practice. In general, there was poor satisfaction from the surveyed physicians about the organizational climate which would explain the poor compliance with the patients' rights. Implementation of training program resulted in significant improvement in physicians' knowledge and awareness about patients' rights. Conclusion There was poor knowledge about patients' rights. This is related to the organizational climate performance and application of educational program resulted in improved knowledge about patients' rights.
\end{abstract}

Keywords: patient rights, doctors, gynecology, obstetrics.

Corresponding Author: Ghada Mahmoud; Ghadamahmoud2975@icloud.com,

\section{Introduction}

Patient rights are defined as the rules of conduct between the people who benefit from health services and the health institutions and personnel who provide them. They are a special case of the broadly defined human rights. ${ }^{1}$ Such rights include observance of acceptable patient physical, mental, spiritual, and social needs guided by commonly accepted rules and regulations. ${ }^{2}$ Patient bill of rights (PBR) calls for equal rights to access health services for all patients. It makes a foundation for preserving good relationships between patients, doctors, and other healthcare staffs. ${ }^{3}$

Patients and health care providers lack necessary knowledge about the patient bill of rights. More dissemination of information about the bill, taking into account the particularities of the corresponding population is needed. ${ }^{4}$

Organizational learning is considered an important factor influencing health care 
quality and patient rights. However, there is little evidence regarding this issue. ${ }^{5}$

In Egypt there was no well-established document to protect patient rights, as the rights of the patient are safeguarded worldwide by laws but Egypt lacks that kind of document which explain clearly the patient rights except for the part which should be implemented during the accreditation program, from here came the idea for community writing for patient bill of rights which began in December 2013 and is finalized by March 2015. ${ }^{6}$

\section{Method}

The current study is an interventional study that was conducted in Zagazig general hospital as it is the gatekeeper in Sharkia, in the department of gynecology and obstetrics as it provides primary healthcare services and there were many complaints from patients admitted to this department.

The study included a total of 70 doctors divided as follow: (11 consultants, 35 specialists and 25 resident doctors). The study included physicians accepting to share in the program and working in the department for more than 6 months.

Data Collection Tool: A structured questionnaire was developed inquiring about (a) relevant personal data and environmental working condition including age, work duration, Knowledge about patient rights and its effect on their practice. (b) Standard for healthcare accreditation of MOHP regarding patient rights (The doctor tell the patient about his name, The doctor respects the patient values and beliefs, The doctor obtains informed consent before (surgery, family planning interventions, anesthesia, blood and its products use, high risk procedures), The doctor respects the privacy of the patient, The doctor explains the case, the management plan and the side effects of the treatment to the
Table (1): Basic Data of The Studied Group (n=70)

\begin{tabular}{|c|c|c|c|}
\hline & Variables & No & $\%$ \\
\hline \multirow{3}{*}{ 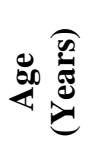 } & $25-35$ & 6 & 14.3 \\
\hline & $35-45$ & 31 & 40.0 \\
\hline & $45-60$ & 33 & 45.7 \\
\hline \multirow{2}{*}{ ¿্் } & Male & 38 & 54.3 \\
\hline & Female & 32 & 45.7 \\
\hline \multirow{4}{*}{ 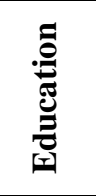 } & Resident & 15 & 17.2 \\
\hline & Assistant specialist & 15 & 11.4 \\
\hline & Specialist & 24 & 40.0 \\
\hline & Consultant & 16 & 31.4 \\
\hline \multirow{3}{*}{ 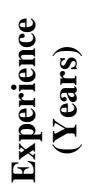 } & $1-$ & 12 & 17.2 \\
\hline & $5-10$ & 20 & 28.5 \\
\hline & $>10$ & 38 & 54.3 \\
\hline \multirow{3}{*}{ 응 $\frac{\tilde{0}}{\stackrel{0}{\frac{\pi}{5}}}$} & Satisfied & 29 & 41.4 \\
\hline & Partially satisfied & 35 & 50.0 \\
\hline & Not satisfied & 6 & 8.6 \\
\hline
\end{tabular}

patient, The doctor shares the patient in decisions related to his treatment, The doctor tells the patient the price of the service, The doctor takes general consent when admitting the patient, The doctor listens to the patient carefully). (c) Questionnaire for organizational climate to identify factors underlying poor practice about patient rights (organizational design category, individual job characteristics, co-work relations, culture/work environment, senior management, direct supervisor, work process category, communications category, technology category, customer satisfaction. (d) Questionnaire for gap analysis process (In your opinion, what is the cause of this problem and how to solve this problem?)

Operational design

Preparatory phase: The researcher reviewed the past and current related literature, textbooks, journals and internet services. The personal and environmental working condition

Table (2): Job Awareness, Attitude and Practice of Physicians regarding Patient Rights. 


\begin{tabular}{|c|c|c|c|}
\hline Vari & & $\mathbf{N}$ & $\%$ \\
\hline Knowledge about & Yes & 57 & 51.4 \\
\hline rights standards & No & 13 & 48.6 \\
\hline \multirow{2}{*}{ Source of knowledge } & Official & 33 & 44.3 \\
\hline & Non-official & 24 & 7.1 \\
\hline \multirow{5}{*}{$\begin{array}{l}\text { Strong attention to patients' } \\
\text { rights' practice }\end{array}$} & Always & 19 & 7.1 \\
\hline & Often & 20 & 21.4 \\
\hline & Sometimes & 13 & 20.0 \\
\hline & Rarely & 3 & 2.9 \\
\hline & Never & 2 & 48.6 \\
\hline \multirow{2}{*}{ Effect on practice } & Yes & 42 & 51.4 \\
\hline & No & 15 & 48.6 \\
\hline \multirow{3}{*}{ Percent of effect on practice } & $95 \%$ & 12 & 16.6 \\
\hline & $70.0 \%$ & 23 & 63.5 \\
\hline & $50.0 \%$ & 7 & 19.4 \\
\hline
\end{tabular}

Table (3): Organizational Climate Adequacy as reported by Physicians ( $N=70)$

\begin{tabular}{lll}
\hline \multicolumn{1}{c}{ Adequate organizational climate } & N & \% \\
\hline Organizational design & 42 & 60.0 \\
Individual job characteristics & 19 & 27.1 \\
Co-work relations & 29 & 41.4 \\
Culture/work environment & 27 & 38.6 \\
Senior management & 39 & 55.7 \\
Direct supervisor & 21 & 30.0 \\
Work process & 42 & 60.0 \\
Communication & 23 & 42.6 \\
Technology & 27 & 38.6 \\
\hline Customer satisfaction & 20 & 28.6 \\
\hline$\bullet \quad$ Adequate $(60 \%+)$ & 13 & 18.6 \\
$\bullet \quad$ Inadequate $(<60 \%)$ & 41 & 58.6 \\
\hline
\end{tabular}

questionnaire was designed and the MOHP quality standards in patient rights were reviewed. Pilot on $10 \%$ of the sample to check the validity and feasibility of the practical work, no changes has been needed to be done.

Implementation phase: $1^{\text {st }}$ phase: Filling the questionnaire and assessing the doctors' practice regarding patient rights in the gynecology and obstetrics department by observation. $2^{\text {nd }}$ phase: It includes gap analysis between the standard and the practice and identification and determination of the defects. Structure the training program according to the defects. Detection of the causes of the gaps defect by pareto chart. 3rd phase: Structure of the training program according to the defects: The doctors are subdivided into 2 categories the $1^{\text {st }}$ include resident and assistant specialist doctors and the $2^{\text {nd }}$ include the specialists and consultants.

Data show was done about patient rights standards. Outsprints are delivered to the doctors.

$4^{\text {th }}$ phase: Evaluation of the effect of the training program was done three months later after the training through comparing practice before and after the program.

\section{Statistical analysis}

Data obtained from the present study were computed using SPSS

Table (4): Gap Analysis Questionnaire 


\begin{tabular}{|c|c|c|c|c|c|}
\hline & \multirow{2}{*}{ Questions } & \multicolumn{2}{|c|}{ Yes } & \multicolumn{2}{|c|}{ No } \\
\hline & & $\mathbf{N}$ & $\%$ & $\mathbf{N}$ & $\%$ \\
\hline 1 & Do you see that there is a problem in patient rights practice & 70 & 100 & 0 & 0 \\
\hline \multicolumn{6}{|c|}{ In your opinion, what is the cause of this problem } \\
\hline \multirow{6}{*}{2} & The doctors aren't well trained on the patient rights standards. & 70 & 100 & 0 & 0 \\
\hline & The doctors aren't aware about patient rights practice & 67 & 95.7 & 3 & 4.3 \\
\hline & Decreased number of doctors in the unit. & 29 & 41.4 & 41 & 48.6 \\
\hline & Overcrowding of the patients in the unit & 26 & 37 & 44 & 62.9 \\
\hline & Lack of supervision & 11 & 15.7 & 59 & 84.3 \\
\hline & Deficient tools & 7 & 10 & 68 & 97 \\
\hline \multirow{9}{*}{3} & In your opinion, how to solve this problem & & & & \\
\hline & Training of the doctors about standards & 70 & 100 & 0 & 0 \\
\hline & Training about implementation of the standards & 70 & 100 & 0 & 0 \\
\hline & Increase the number of the doctors in the unit & 39 & 55.7 & 31 & 44.3 \\
\hline & Increase the time of the work & 13 & 18.6 & 57 & 81.4 \\
\hline & Training of doctors about communication skills & 67 & 95.7 & 3 & 4.3 \\
\hline & To enter the computer system in the unit & 24 & 34.3 & 46 & 65.7 \\
\hline & $\begin{array}{l}\text { Containment of the head of the unit with the standard of the } \\
\text { patient rights and to supervise other doctors }\end{array}$ & 36 & 51.4 & 34 & 48.6 \\
\hline & Make consent form available & 21 & 30.0 & 49 & 70.0 \\
\hline
\end{tabular}

version 22. Continuous data were expressed in the form of mean $\pm \mathrm{SD}$ while categorical data were expressed in the form of count and percent. Comparison of continuous data was performed utilizing paired $t$ test. $\mathrm{P}$ value less than 0.05 was considered statistically significant.

\section{Ethical Consideration}

The approval was obtained from Zagazig University Institutional Review Board (IRB)

\section{Results}

The age of doctors ranged from 25-35 years in 6 physicians $(14.3 \%)$ to $35-45$ years in 31 physicians $(40.0 \%)$ and $45-$ 60 years in 33 physicians $(45.7 \%)$. They comprised 38 males $(54.3 \%)$ and 32 females $(45.7 \%)$. The educational level was resident in $12(17.2 \%)$, assistant specialist in $8(11.4 \%)$, specialist in 28 $(40.0 \%)$ and consultant in 22 physicians
$(31.4 \%)$. About $(17.2 \%)$ of the studied physicians had 1-5 years of experience, while 20 physicians $(28.5 \%)$ had 5-10 years of experience and 38 physicians $(54.3 \%)$ had experience exceeding 10 years. [Table-1]

The majority of physicians $52 \%$ knew about the presence of patient rights standard and (49\%) of them never pay attention to practicing it. Regarding the effect on practice it was found that about $63 \%$ of doctors were affected by about 70\%. [Table-2]

The majority of physicians reported adequacy in the items of organizational design, senior management and work process, where other items were inadequate as shown in table (3). The doctors' response to the standards of patients' rights was below average with only Q1 above $50 \%$ and the other questions from $40-50 \%$.

The problem of patient rights practice and how to solve it (gap questionnaire) as

Table (5): Pre and Post Interventional Response of The Studied Group to The Patients' Rights Questionnaire 


\begin{tabular}{|c|c|c|c|c|c|c|c|c|c|c|}
\hline \multirow{3}{*}{ Questions } & \multicolumn{4}{|c|}{ Pre-interventional } & \multicolumn{4}{|c|}{ Post interventional } & \multirow{3}{*}{$\begin{array}{c}\text { Chi- } \\
\text { square } \\
\mathrm{X}^{2} \\
\end{array}$} & \multirow{3}{*}{$P$ value } \\
\hline & \multicolumn{2}{|c|}{ Yes } & \multicolumn{2}{|c|}{ No } & \multicolumn{2}{|c|}{ Yes } & \multicolumn{2}{|c|}{ No } & & \\
\hline & $\mathbf{N}$ & $\%$ & $\mathbf{n}$ & $\%$ & $\mathbf{n}$ & $\%$ & $\mathbf{n}$ & $\%$ & & \\
\hline $\begin{array}{l}\text { Doctor tell } \\
\text { his name }\end{array}$ & 56 & 80.0 & 14 & 20.0 & 66 & 94.3 & 4 & 5.7 & 6.4 & $0.012 *$ \\
\hline $\begin{array}{l}\text { Respect } \\
\text { values }\end{array}$ & 60 & 85.7 & 10 & 14.3 & 67 & 95.7 & 3 & 4.3 & 4.2 & $0.042 *$ \\
\hline $\begin{array}{l}\text { Informed } \\
\text { consent }\end{array}$ & 22 & 31.4 & 48 & 68.6 & 63 & 90.0 & 7 & 10.0 & 50.3 & $0.0001 *$ \\
\hline $\begin{array}{l}\text { Patient } \\
\text { privacy }\end{array}$ & 23 & 32.9 & 47 & 67.1 & 59 & 84.3 & 11 & 15.7 & 38.2 & $0.0001 *$ \\
\hline $\begin{array}{l}\text { Case } \\
\text { explanation }\end{array}$ & 22 & 31.4 & 48 & 68.6 & 60 & 85.7 & 10 & 14.3 & 42.5 & $0.0001 *$ \\
\hline $\begin{array}{l}\text { Sharing } \\
\text { decision }\end{array}$ & 12 & 17.1 & 58 & 82.9 & 62 & 88.6 & 8 & 11.4 & 71.7 & $0.0001 *$ \\
\hline $\begin{array}{l}\text { Service } \\
\text { price }\end{array}$ & 10 & 14.3 & 60 & 85.7 & 55 & 78.6 & 15 & 21.4 & 58.2 & $0.0001 *$ \\
\hline $\begin{array}{l}\text { General } \\
\text { consent }\end{array}$ & 11 & 15.7 & 59 & 84.3 & 56 & 80.0 & 14 & 20.0 & 58.0 & $0.0001 *$ \\
\hline Listening & 9 & 12.9 & 61 & 87.1 & 60 & 85.7 & 10 & 14.3 & 74.3 & $0.0001^{*}$ \\
\hline
\end{tabular}

reported from physicians were illustrated in [Table-4].

It was noticed that the entire physician feel that there is problem in the practice of patient rights. By asking them about the causes, it was found that $90 \%$ of doctors are not well trained about the standards as well as about the implementation of it. About 29\% mentioned that the cause was decreased number of doctors in the unit. About 26\% mentioned that the cause is overcrowding of the patient in the unit. While $11 \%$ referred the reason to the lack of supervision from senior manager. $7 \%$ mentioned that deficient tools like consent forms and lack of bed partitions is the cause [Table-4]. Pareto chart illustrated that about $80 \%$ of the problem can be solved by solving the vital $20 \%$ of causes.

There was no significant relation between response to patients' rights questionnaire and professional level before intervention. But there was significant improvement of all items of the patients' rights questionnaire as shown in [Table-5].

\section{Discussion}

Patients and health care providers lack necessary knowledge about the patient rights. More dissemination of information about these rights, taking into account the particularities of the corresponding population is needed. ${ }^{4}$

The present study aimed to assess the patient rights application according to the standards of ministry of health and population, to identify factors underlying poor practice about patient rights among doctors, to design and implement intervention training program to the doctors and to assess the effects of training program on the doctors' practice.

The study recruited 70 physicians. They were subjected to patients' rights' questionnaire and on the basis of gap analysis between the current practice and required standards, an educational program was designed and implemented.

The current study showed that only $51.4 \%$ of the studied physicians were aware about patients' rights. Moreover, there was poor attention to patients' rights' practice as more than half of the study population rarely or never paid attention to patients' rights during practice. In addition, nearly $50.0 \%$ of participants perceived that patients' rights have influence on medical practice. 
Furthermore, there was generally poor compliance with the patients' rights standards.

In one Finnish study, data were collected from healthcare professionals (nurses and physicians) in public health care with a questionnaire designed for the study. The study found that healthcare professionals were partially familiar with patients' legal rights. The right to good health care, treatment and access to care and right to selfdetermination were the best-known areas. The respondents lacked knowledge on the right to information and the right to use the services. Based on self-evaluation, half of the respondents thought that they had weak knowledge of the legislation on patients' rights. However, they perceived knowledge about patients' rights as being important. ${ }^{7}$

Similar data were obtained from the Egyptian study of Abou Zeina et al. ${ }^{8}$ In their work, they examined the awareness of and practices regarding patients' rights in one of the general hospitals in South Egypt. The cross-sectional study incorporated a convenience sample of the hospitalized patients and their companions $(\mathrm{N}=292)$, as well as the actively working medical care providers (MCPs) at the time of data collection, 72 physicians and 48 nurses. The authors found that about $50.0 \%$ of MCPs did not know about the list of patients' rights.

The situation was even worse in the Ugandan study of Kagoya et al., ${ }^{9}$ where level of awareness of, responsiveness to and practice of patients' rights amongst patients and health workers (HWs) at Uganda's national referral hospital were evaluated. The study noted that most patients $(81.5 \%)$ and HWs $(69.4 \%)$ had never heard of the Uganda Patients' Charter.

Also, we are in agreement with the study of Al-Muammar and Gari ${ }^{10}$ that assessed the level of physicians' knowledge about the contents of patients' bill of rights (PBR) and its implementation at Saudi hospital. Merely, about $44.5 \%$ of physicians had adequate knowledge about PBR and 55.5\% had inadequate knowledge.

In contrast, the Iranian study of Sabzevari et al. ${ }^{11}$ that evaluated observance of the Patients' Rights Charter among medical staff of educational hospitals, found that observance of human rights was perfect by 84.4 percent of subjects. The highest amount of observance of patients' rights was related to the area of respecting patients' privacy and observing the principle of confidentiality, which was evaluated to be perfect by all subjects (100\%). The lowest value of patients' rights observance was related to presenting appropriate and adequate information for patients, which was perfect among $48.1 \%$ of subjects.

In its pursuit for effective solution of the problem, our study performed a gap analysis using a structured questionnaire to identify the magnitude of the problem, its causes and probable solutions. Most participants agreed that there is a problem with patients' rights awareness and implementation.

This is line with the study of Alcheva et al. ${ }^{12}$ from Macedonia that aimed to highlight the gaps in the implementation of patients' rights implementation on the ground. They found that that in spite of the strong legislative basis of patients' rights, the implementation of many key provisions is lacking, both in terms of quality and presence of services or mechanisms contemplated by law.

For more sophisticated analysis, the present study assessed the perception of the studied physicians of the different domains of organizational climate. In general, there was poor satisfaction from the surveyed physicians about the organizational climate which would explain the poor compliance of the medical workers with the patients' rights. Also, the study of Peña-Viveros et al. ${ }^{13}$ that aimed identify the relationship between organizational climate of management teams and the performance of health services found a positive correlation was demonstrated between organizational climate level and performance. 
Moreover, the study of Bahrami et al. ${ }^{14}$ noted a positive and significant correlation between organizational commitment and organizational climate.

Most recently, Berberoglu ${ }^{15}$ concluded that positive organizational climate leads to higher levels of organizational commitment, which is an important concept in terms of employee attitudes, likewise, the concept of perceived organizational performance, which can be assumed as a mirror of the actual performance.

In the present study, implementation of training program resulted in significant improvement in physicians' knowledge and awareness about patients' rights.

These data are in line with the study of Elsayed et al. ${ }^{16}$ evaluated the effect of an educational intervention on nurses' awareness about patients' rights. The study found that there is a significant improvement of nurses' awareness about patients' rights after the educational intervention

In accordance with our appraoch, the study of Abedian et al. ${ }^{17}$ tried to determine the effect of an education-based intervention on self- reported awareness and practice in observing patients' rights. Repeated measure analysis of variance test showed a significant difference in awareness and practice before and after intervention.

Likewise, we are in agreement with the study of Ibrahim et al. ${ }^{18}$ who studied the effect of training sessions about patients' rights in two Egyptian hospitals. The training sessions were developed based on the baseline information gathered in the assessment phase. Results showed that improvement in knowledge and perceptions about patients' rights after implementation of the training sessions was remarkable.

\section{Conclusion}

There is poor knowledge and implementation of patients' rights. This is related to the organizational climate performance and application of educational program resulted in improved knowledge about patients' rights.

\section{Recommendations}

Organizational education of patients' rights should be essential element of health worker education and training. A larger multi-institutional study is recommended to confirm results of the present study.

\section{References:}

1. Kiełbasa S, Niedzielski A. [Social awareness related to the rights of the patient and knowledge of the possible actions in case of a breach of those under 30 years old]. Pol Merkur Lekarski. 2015 Jun; 38(228):320-5.

2. Abedi G, Shojaee J, Moosazadeh M, Rostami F, Nadi A, Abedini E, Palenik CJ, Askarian M. Awareness and Observance of Patient Rights from the Perspective of Iranian Patients: A Systematic Review and Meta-Analysis. Iran J Med Sci. 2017 May; 42(3):227-234.

3. Abbasi S, Ferdosi M. Do electronic health records standards help implementing patient bill of rights in hospitals? Acta Inform Med. 2013 Mar; 21(1):20-2.

4. Alghanim SA. Assessing knowledge of the patient bill of rights in central Saudi Arabia: a survey of primary health care providers and recipients. Ann Saudi Med. 2012 Mar-Apr; 32(2):151-5.

5. Heidari S, Nayeri ND, Ravari A, Sabzevari S. How organizational learning is associated with patient rights: qualitative content analysis. Glob Health Action. 2016 Jul 26; 9:30939.

6. Alaa Ghannam, Ayman seven expert in the health sector reform program and a researcher the right to health of the Egyptian Initiative for Personal Rights Shorouk News, Friday, June 19 2015 http://www.shorouknews.com/columns/ view.

7. Iltanen S, Leino-Kilpi H, Puukka P, Suhonen R. Knowledge about patients' rights among professionals in public health care in Finland. Scand J Caring Sci. 2012 Sep;26(3):436-48.

8. Abou Zeina HA, El Nouman AA, Zayed MA, Hifnawy T, El Shabrawy EM, El Tahlawy E. Patients' rights: a hospital survey in South Egypt. J Empir Res Hum Res Ethics. 2013 Jul;8(3):4652. 
9. Kagoya HR, Kibuule D, Mitonga-Kabwebwe H, Ekirapa-Kiracho E, Ssempebwa JC.Awareness of, responsiveness to and practice of patients' rights at Uganda's national referral hospital. Afr J Prim Health Care Fam Med. 2013 Jun 21;5(1).

10. Al-Muammar SA, Gari DMK. Doctors' knowledge of patients' rights at King Fahd Hospital of the University. J Family Community Med. 2017 May-Aug;24(2):106-110.

11. Sabzevari A, Kiani MA, Saeidi M, Jafari SA, Kianifar H, Ahanchian H, Jarahi L,Zakerian M. Evaluation of Patients' Rights Observance According to Patients'Rights Charter in Educational Hospitals Affiliated to Mashhad University of Medical Sciences: Medical Staffs' Views. Electron Physician. 2016 Oct 25;8(10):3102-3109.

12. Alcheva G, Gerovski F, Beletsky L. Implementation of patients' rights legislation in the Republic of Macedonia: gaps and disparities. Health Hum Rights. 2013 Dec 12;15(2):20-31. 13. Peña-Viveros R, Hernández-Hernández DM, Vélez-Moreno AM, García-Sandoval MG, Reyes-Tellez MA, Ureña-Bogarin EL. [Organizational climate in management teams and its relationship with health care outcomes].
Salud Publica Mex. 2015 Nov-Dec; 57(6):52836.

14. Bahrami MA, Barati O, Ghoroghchian MS, Montazer-Alfaraj R, Ranjbar Ezzatabadi M. Role of Organizational Climate in Organizational Commitment: The Case of Teaching Hospitals. Osong Public Health Res Perspect. 2016 Apr;7(2):96-100.

15. Berberoglu A. Impact of organizational climate on organizational commitment and perceived organizational performance: empirical evidence from public hospitals. BMC Health Serv Res. 2018 Jun 1;18(1):399.

16. Elsayed KA; El-melegy OA; Amaal M. The effect of an educational intervention on nurses' awareness about patients' Rights in Tanta. Journal of American Science, 2013, 9.9: 210219.

17. Abedian K, Bagheri Nesami M, Shahhosseini Z. The effect of an education-based intervention on self-reported awareness and practice of Iranian nurses in observing patients' rights. Glob J Health Sci. 2014 Nov 17;7(3):98104.

18. Ibrahim SA, Hassan MA, Hamouda SI, Abd Allah NM. Effect of patients' rights training sessions for nurses on perceptions of nurses and patients. Nurs Ethics. 2017 Nov;24(7):856-867. 